\title{
Methotrexate and liver toxicity: role of surveillance liver biopsy Conflict between guidelines for rheumatologists and dermatologists
}

Methotrexate has been used successfully for the treatment of psoriasis since 1951, and over the past decade its use has increased significantly in the treatment of psoriatic arthritis and rheumatoid arthritis. The potential for hepatic toxicity remains a concern to physicians who are increasingly using this drug.

The American Association of Dermatology has specific guidelines for monitoring the hepatic toxicity of methotrexate in patients with psoriasis. ${ }^{1}$ These recommend a baseline liver biopsy at or near the beginning of methotrexate treatment and after each cumulative dose of $1.5 \mathrm{~g}$, to detect histological abnormalities (table 1). Because there were no published data concerning the liver toxicity of methotrexate in patients with rheumatoid arthritis, many rheumatologists initially followed the dermatology guidelines and obtained biopsy specimens before treatment and frequently thereafter. However, as the use of methotrexate increased, it emerged that clinically serious liver disease was less common in patients with rheumatoid arthritis than in those with psoriasis. The pendulum has consequently now swung to the other extreme, with rheumatologists infrequently performing liver biopsy-a practice that is further enforced by recently published guidelines from the American College of Rheumatology: ${ }^{2}$ on the basis of findings of a very low incidence of histological abnormalities in patients with rheumatoid arthritis who are taking methotrexate, surveillance liver biopsying is not recommended (table 2). However, patients with a prior excessive alcohol consumption, persistently increased ab-

Table 1 Methotrexate in psoriasis: revised guidelines

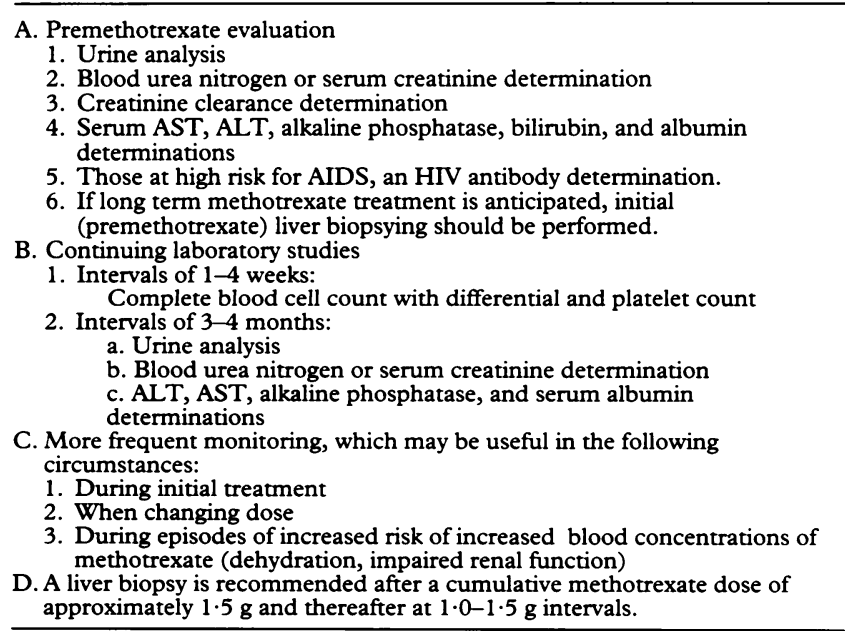

normal baseline concentrations of serum aspartate aminotransferase (AST), or those with chronic hepatitis B and $C$ infection should be considered for pretreatment liver biopsying. In contrast with the recommendations of the dermatology guidelines, liver biopsying in patients with rheumatoid arthritis during treatment with methotrexate is recommended only if, in a 12 month period, five of the nine determinations of AST are abnormal (six of 12 if monitoring is monthly), or if there is a decrease in serum albumin below the normal range in patients with well controlled rheumatoid arthritis. However, unlike patients with rheumatoid arthritis who are taking methotrexate, patients with psoriasis who are taking this drug have been reported to show a lack of correlation between liver function abnormalities and liver histology, ${ }^{2-4}$ therefore liver biopsy is recommended after each cumulative dose of 1-1.5 $\mathrm{g}$ of methotrexate in patients with psoriasis.

The exact cause of the differences in the liver toxicity of methotrexate in patients with rheumatoid arthritis and in those with psoriasis is unknown. However, heavy alcohol consumption and cumulative dose of methotrexate perhaps play a major part. ${ }^{5}$ Although there are no comparative studies of patients with rheumatoid arthritis and those with psoriasis regarding alcohol intake, there is a well established link between psoriasis and high alcohol intake. ${ }^{6}$ This may explain the observation of increased abnormality of liver histology in patients with psoriasis compared with those with rheumatoid arthritis before commencing methotrexate. ${ }^{5}$ Other reported risk factors include obesity,

Table 2 Recommendations for monitoring hepatic toxicity in patients with rheumatoid arthritis $(R A)$ receiving methotrexate

\footnotetext{
A. Baseline

1. Tests for all patients

a. Liver blood tests (aspartate aminotransferase (AST), alanine aminotransferase (ALT), alkaline phosphatase, albumin, bilirubin), hepatitis $B$ and $C$ serological studies. b. Other standard tests, including complete cell count and serum creatinine.

2. Pretreatment liver biopsy (Menghini suction-type needle) only for patients with:

a. Prior excessive alcohol consumption

a. Prior excessive alcohol consumption
b. Persistently abnormal baseline AST values c. Chronic hepatitis B or C infection.

B. Monitor AST, ALT, albumin at 4-8 week intervals

C. Perform liver biopsy if:

1. Five of nine determinations of AST within a given 12 month interval (six of 12 if tests are performed monthly) are abnormal (defined as an increase above the upper limit of normal)

2. There is a decrease in serum albumin below the normal range (in the setting of well controlled $R A$ )

D. If results of liver biopsy are:

3. Roenigk grade I, II, or IIA, resume methotrexate and monitor as in B, $\mathrm{C} 1$, and $\mathrm{C} 2$ above.

4. Roenigk grade IIIB or IV, discontinue methotrexate

E. Discontinue methotrexate in patients with persistent liver test abnormalities, as defined in $\mathrm{C} 1$ and $\mathrm{C} 2$ above, or who refuse liver biopsy
} 
diabetes mellitus, congestive cardiac failure, and Felty's syndrome. ${ }^{78}$ Other factors such as disease per se, HLA status, and drug interaction may play an important part in causing methotrexate toxicity. It is surprising that liver toxicity is not more common in patients with rheumatoid arthritis, as most also take non-steroidal anti-inflammatory drugs, which increase the toxic effects of methotrexate. Whether prior psoralen ultraviolet A (PUVA) or retinoid treatment for psoriasis might contribute to methotrexate toxicity is not yet known.

There are a number of differences between patients with psoriasis only and those with psoriatic arthritis. Whilst it is possible to have severe skin involvement and no joint disease, it is rare to have severe joint disease without any skin disease, and generally there is a relationship between the severity of skin disease and the frequency of joint disease. Psoriatic arthritis is reported to be more commonly associated with pustular and erythrodermic psoriasis. ${ }^{9}$ There is convincing evidence of genetic (HLA) differences between psoriasis and psoriatic arthritis. ${ }^{10} \mathrm{High}$ alcohol intake is common amongst patients with psoriasis, but whether there are differences in the amounts of alcohol consumed by patients with psoriasis compared with those with psoriatic arthritis is not known. There are significant differences between patients with psoriasis and those with psoriatic arthritis, but from the published studies it is difficult to assess whether the two categories of patients have the same frequency of liver histology abnormalities before and during methotrexate treatment. Most of the studies assessing the hepatic toxicity of methotrexate in patients with psoriasis have not given details of the frequency of psoriatic arthritis in their patients. ${ }^{11}$ Furthermore, different studies have used different methods for grading liver biopsy findings in patients receiving methotrexate, and it is difficult to compare findings between the studies. ${ }^{2}$ From the published studies it is therefore difficult in general to ascertain whether there is any significant difference between patients with psoriasis and those with psoriatic arthritis with regard to the hepatic toxicity of methotrexate (table 3 ). There is a need for further studies to answer these questions.

While liver biopsying is generally a safe procedure, it can lead to serious complications such as subcapsular haemorrhage, intraperitoneal bleeding, gallbladder perforation, bile peritonitis, and pneumothorax. The overall risk associated with liver biopsying is approximately 1.5 in 1000 procedures and the mortality varies from $0 \%$ to $0.12 \%$, with an average of $0.03 \% .^{2}$ There are no published British data on the cost of the procedure, but in the US

Table 3 Reported findings of liver histology studies during methotrexate treatment in patients with psoriatic arthritis, psoriasis, and rheumatoid arthritis $(R A)$

\begin{tabular}{|c|c|c|c|}
\hline Source & No of patients & Disease group & $\begin{array}{l}\text { Advanced changes } \\
\text { (No of patients) }\end{array}$ \\
\hline Espinoza $e t a^{5}$ & 40 & Psoriatic arthritis & 1 \\
\hline Themido et al ${ }^{12}$ & 30 & Psoriasis & 3 \\
\hline Zachariae et al ${ }^{13}$ & 183 & Psoriasis & 19 \\
\hline Rademaker et al ${ }^{14}$ & 40 & Psoriasis & 0 \\
\hline Nyfors $^{15}$ & 160 & Psoriasis & 14 \\
\hline Dooren-Greebe et al ${ }^{4}$ & 55 & Psoriasis & 3 \\
\hline Hoffmeister ${ }^{16}$ & 34 & RA & 0 \\
\hline Boh et al ${ }^{17}$ & 21 & $\mathrm{RA}$ & 0 \\
\hline Weinblatt et al ${ }^{18}$ & 17 & $\mathrm{RA}$ & 0 \\
\hline Willkens et al ${ }^{19}$ & 52 & $\mathrm{RA}$ & 0 \\
\hline Shergy et al ${ }^{20}$ & 210 & RA & 0 \\
\hline Brick et $a l^{21}$ & 69 & RA & 1 \\
\hline Kremer et $\mathrm{al}^{3}$ & 27 & RA & 0 \\
\hline Aponte et al ${ }^{22}$ & 21 & RA & 2 \\
\hline Raux et al 23 & 40 & RA & $\overrightarrow{1}$ \\
\hline Tolman et al ${ }^{24}$ & 82 & RA & 1 \\
\hline Phillips et al ${ }^{8}$ & 45 & RA & 3 \\
\hline Sawitzke et al 25 & 38 & RA & 0 \\
\hline
\end{tabular}

^Biopsy specimen graded according to the classification described by Roenigk et al the cost of uncomplicated liver biopsy ranges from $\$ 942$ to $\$ 1500 ;^{2}$ this is substantially increased if there are any associated complications. Regular monitoring of patients taking methotrexate by liver biopsying can therefore lead to serious complications with significant cost implications.

The use of methotrexate in the treatment of psoriatic arthritis is increasing. Psoriatic arthritis develops in up to $5-7 \%$ of patients with psoriasis. If they are referred to a rheumatologist, their treatment is usually commenced with sulphasalazine. If response to treatment is inadequate, methotrexate is the drug of choice. Because of the paucity of data regarding the liver toxicity of methotrexate in patients with psoriatic arthritis, many rheumatologists have adopted the same guidelines for monitoring liver toxicity in these patients as are used for the patients with rheumatoid arthritis taking methotrexate. As patients with severe psoriasis and arthritis are usually jointly managed by dermatologist and rheumatologist, the conflicting guidelines from the two specialties can create difficulties in their management. Therefore, until further information is available, it would be prudent to monitor liver toxicity very closely in patients with psoriatic arthritis who are taking methotrexate. I would suggest pretreatment liver biopsying in patients with psoriatic arthritis if they have persistently abnormal baseline AST values, prior excessive alcohol consumption, or chronic hepatitis $\mathrm{B}$ or $\mathrm{C}$ infection.

Department of Rheumatology, District General Hospital, W WASSAN Sunderland SR4 7TP, United Kingdom

1 Roenigk H H Jr, Auerbach R, Maibach H I, Weinstein G D. Methotrexate in psoriasis: revised guidelines. $\mathcal{F}$ Am Acad Dermatol 1988; 19: 145-56.

2 Kremer J M, Alacron G S, Lightfoot R W, et al. Methotrexate for rheumatoid arthritis. Suggested guidelines for monitoring liver toxicity. Arthritis Rheum 1994; 37: 316-28.

3 Kremer J M, Lee R G, Tolman K G. Liver histology in rheumatoid arthritis patients receiving long-term methotrexate therapy: a prospective study with baseline and sequential biopsy samples. Arthritis Rheum 1989; 32: 121-7.

4 Dooran-Greebe $R$ J, Kuijpers A L A, Mulder J, De Boo $T H$ Van De Kerkhof P C M. Methotrexate revisited: effects of long-term treatment in psoriasis. $B r f$ Dermatol 1994; 130: 204-10.

5 Espinoza L, Zakraoui L, Espinoza C G, et al. Psoriatic arthritis: Clinical response and side effects to methotrexate therapy. $\mathcal{F}$ Rheumatol 1992; 19 872-7.

6 Poikolainen K, Reunala T, Karvonen J, Lauharanta J, Karkainen P. Alcohol intake: a risk factor for psoriasis in young and middle aged men? $B M^{f}$ 1990; 300: 780-3.

7 Minocha A, Dean H A, Pittsley R A. Liver cirrhosis in rheumatoid arthritis patients treated with long-term methotrexate. Vet Hum Toxicol 1993; 35: 45-8.

8 Phillips C A, Cera P J, Mangan T F, Newman E D. Clinical liver disease in patients with rheumatoid arthritis taking methotrexate. 7 Rheumatol in patients with

9 Baker H, Golging D N, Thompson M. Psoriasis and arthritis. Ann Int Med 1963; 58: 909-25.

10 Eastmond C J. Genetics and HLA antigens. In: Wright V, Helliwell P, eds. Bailliere's Clinical Rheumatology, Vol 8, No 2. Psoriatic arthritis. London Bailliere Tindall, 1994; 263-76.

11 Whiting-O'Keefe Q E, Fye K H, Sack K D. Methotrexate and histologic hepatic abnormalities: a meta-analysis. $A m$ f Med 1991; 90: 711-6.

12 Themido R, Loureiro M, Pecegueiro M, Brandao M, Campos M C Methotrexate hepatotoxicity in psoriatic patients submitted to long-term therapy. Acta Derm Venerol 1992; 72: 361-4.

13 Zachariae $\mathrm{H}$, Kragballe K, Sogaard $\mathrm{H}$. Methotrexate induced liver cirrhosis. Studies including serial liver biopsies during continued treatment. $\mathrm{Br} \mathcal{\jmath}$ Dermatol 1980; 102: 407-12.

14 Rademaker M, Webb J A W, Lowe D G, Meyrick-Thomas $R H$ Kirby J D T, Munro D D. Magnetic resonance imaging as a screening procedure for methotrexate induced liver damage. Br $\mathcal{F}$ Dermatol 1987 117: $311-6$.

15 Nyfors A. Liver biopsies from psoriatics related to methotrexate therapy. Acta Pathol Microbiol Scand 1977; 85: 511-8.

16 Hoffmeister R T. Methotrexate in rheumatoid arthritis [abstract]. Arthritis Rheum 1972; 15: 114

17 Boh L E, Schuna A A, Pitterle M E, Adams E M, Sundstrom W R. Low dose weekly oral methotrexate therapy for inflammatory arthritis. Clin Pharm 1986; 5: 503-8.

18 Weinblatt M E, Weissman B N, Holdsworth D E, et al. Longterm prospective study of methotrexate in the treatment of rheumatoid arthritis: 84 month update. Arthritis Rheum 1992; 35: 129-37.

19 Willkens R F, Leonard P A, Clegg D O, et al. Liver histology in patients receiving low dose pulse methotrexate for the treatment of rheumatoid arthritis. Ann Rheum Dis 1990; 49: 591-3.

20 Shergy W J, Pollison R P, Caldwell D S, Rice J R, Pisetsky D S, Allen N B. Methotrexate associated hepatotoxicity: retrospective analysis of 210 patients with rheumatoid arthritis. $A m \mathcal{F}$ Med 1988; 85: 771-4.

21 Brick J E, Moreland L W, Al-Kawas F, Chang W W, Layne R D, DiBartolomeo A G. Prospective analysis of liver biopsies before and after DiBartolomeo A G. Prospective analysis of liver biopsies before and after
methotrexate therapy in rheumatoid patients. Semin Arthritis Rheum 1989; 19: 31-44. 
22 Aponte J, Petrelli M. Histopathologic findings in the liver of rheumatoid arthritis patients treated with longterm bolus methotrexate. Arthritis Rheum 1988; 31: 1457-64.

23 Rau R, Karger T, Herborn G, Frenzel H. Liver biopsy findings in patients with rheumatoid arthritis undergoing longterm treatment with methotrexate. $\mathcal{F}$ Rheumatol 1989; 16: 489-93.
24 Tolman K G, Clegg D O, Lee R G, Ward J R. Methotrexate and liver. Arthritis Rheum 1985; 12 (suppl): 29-34.

25 Sawitzke A D, Jackson C G, Lundberg M L, et al. Serial liver biopsies from methotrexate treated rheumatoid arthritis patients [abstract]. Arthritis Rheum 1991; 34 (suppl): S161.

\section{Problems with pain -is the messenger to blame?}

The nature and definition of pain has troubled mankind since the earliest times. To the ancient Greeks, pleasure and pain were closely linked 'passions of the soul', such that the absence of one led inevitably to the other, and vice versa. Two thousand years later, pain remains one of the great challenges facing modern rheumatology. Recent definitions, such as that adopted by the International Association for the Study of Pain, ${ }^{1}$ have attempted to encompass the multidimensional character of pain by emphasising that it is not simply a sensory experience, but that it has important emotional and motivational components as well.

The subjective and private nature of pain means that it is often difficult to describe. Nevertheless, it is essential that the physician obtains a clear description in order to facilitate both diagnosis and assessment of response to treatment. Latterly, a number of techniques have been developed that evaluate pain indirectly using self rating scales, behavioural observational scales, and assessment of physiological responses. ${ }^{2}$ Verbal and numeric pain rating scales, characterised by the visual analogue scale, quantify the intensity and magnitude of pain but do not consider other components. More descriptive scales, such as the McGill pain questionnaire, attempt to quantify these other components and have been used widely to study the effects of various methods of pain management. In clinical practice, however, the use of these instruments has proved less helpful, and the practitioner remains heavily dependent on a good clinical history.

In many patients the origins of musculoskeletal pain are confusing, but experimental studies are now providing valuable insights into the mechanisms by which symptoms may arise. At least in part, the varied range of symptoms can be explained by the often complex relationship between the nervous system and the underlying disease. It is now appreciated that pain depends not only on tissue injury, if any, but also on functional changes within the nervous system. ${ }^{34}$ Neural pathways are inherently plastic and can be extensively modified according to different conditions. The extent of these changes may well vary between individuals, and in some circumstances persist long after the initiating stimulus has resolved.

A key aspect of neurogenic plasticity involves changes to the sensitivity of individual neurones at both peripheral and central levels. Within the joint, injury or inflammation inevitably produce sensitisation and subsequent activation of articular sensory receptors. Different mediators released either by inflammatory cells or from sympathetic nerve terminals produce varying effects on these receptors. ${ }^{5}$ In many if not all arthropathies, the pattern of sensitisation and activation in the periphery is likely to be of pivotal importance in determining the character and magnitude of articular symptoms. It is particularly significant that large numbers of articular nerve fibres are non-responsive under normal conditions and only react following inflammation. ${ }^{6}$ Although direct proof is lacking, this may underly the use related or so called 'incident' pain that is experienced only on joint movement and is not present at rest. It is difficult to treat, as titration of a dose of drug adequate to provide analgesia during joint movement may result in unacceptable toxicity during pain free periods.

Sustained or repetitive activation of peripheral sensory nerves produces substantial changes to the function and activity of central neurogenic pathways. ${ }^{4}$ Once these changes are established, sensory processing is substantially modified and may result in new sensory modalities such as allodynia, whereby normally innocuous stimuli are perceived as being painful. ${ }^{7}$ Changes within central pathways may also be responsible for decreased pain thresholds over apparently normal tissues (secondary hyperalgesia) and for referred pain syndromes. A history of altered and often bizzare symptoms, increased numbers of muscle tender points, or the presence of trigger points may all indicate the presence of central hyperexcitability. At the spinal level, the importance of $N$-methyl-D-aspartate (NMDA) and neurokinin receptors in the genesis of these changes is now appreciated. ${ }^{8}$ Specific targetting of these receptors represents a novel analgesic approach that is currently receiving much attention. ${ }^{9}$ Endogenous opioids have an important inhibitory role, but concerns over inappropriate use continue to limit the use of opioids in musculoskeletal practice. ${ }^{10}$

This edition of the Annals marks the start of a new series devoted to musculoskeletal pain. The first articles in the series review the pathophysiology of peripheral and central mechanisms and attempt to bridge the relatively wide gulf that still exists between experimental findings and clinical observations. The interplay between the environment, personality, and pain perception is then explored, as is the difficult issue of chronic musculoskeletal pain syndromes. The series concludes with an assessment of the suitability of specialised pain clinic techniques for use in more general situations, and the likely impact of novel therapies on treatment of musculoskeletal pain in the future.

St Bartholomew's and Royal London Hospital School of Medicine,

London $12 A D$,

United Kingdom

Classification of chronic pain, second edition. Merskey H, Bogduk N, eds. Seattle: IASP Press, $1994 ; 209-13$

2 Melzack R, Katz J. Pain measurement in persons in pain. In: Wall P D, Melzack $R$, eds. Textbook of pain, third edition. Edinburgh: Churchill Melzack $R$, eds. Textbook of pa

3 Woolf $\mathrm{C} \mathrm{J}$. Evidence for a central component of postinjury pain hypersensitivity. Nature 1983; 308: 686-8.

4 Coderre T J, Katz J, Vaccarino A L, Melzack R. Contribution of central neuroplasticity to pathological pain: review of clinical and experimental evidençe. Pain 1993; 52: 259-85.

Schaible H, Grubb B D. Afferent and spinal mechanisms of joint pain. Pain 1993; 55: 5-54.

6 Grigg P, Schaible H, Schmidt R F. Mechanical sensitivity of group III and IV afferents from posterior articular nerve in normal and inflamed cat knee. F Neurophysiol 1986; 55: 635-43.

7 Torejork H E, Lundeberg L, LaMotte R H. Central changes in processing of mechanoreceptive input in capsaicin-induced secondary hyperalgesia in humans. F Physiol (Lond) 1992; 448: 765-80.

8 Urban L, Thompson SW N, Dray A. Modulation of spinal excitability: cooperation between neurokinin and excitatory amino acid neurotransmitters. Trends Neurosci 1994; 17: 432-8.

9 Rang H P, Urban L. New molecules in analgesia. Br $\mathcal{f}$ Anaesth 1995; 75: $145-56$

10 Brena S F, Sanders S H. Opioids in nonmalignant pain: questions in search of answers. Clin $\mathcal{Y}$ Pain 1991; 7: 346. 